Relato de Caso

CASE REPORT

\title{
Microangiopatia Livedóide Associada à Síndrome do Anticorpo Antifosfolípide (SAF)
}

\author{
Livedoid Microangiopathy Associated to \\ Antiphospholipid Antibody Syndrome (APS)
}

\author{
Carla Munhoz Sanches ${ }^{(1)}$, Fernanda de Carvalho L'Abbate ${ }^{(1)}$, Virginia Fernandes Moça Trevisani ${ }^{(2)}$, \\ Lucia Stella de Assis Goulart(2), Alessandra Bruns ${ }^{(3)}$
}

\section{RESUMO}

A microangiopatia livedóide é uma síndrome de hialinização segmentar crônica dos vasos da derme, de causa desconhecida, que afeta principalmente os membros inferiores. Histopatologicamente, tanto as lesões iniciais quanto as tardias são caracterizadas por infiltrado com escassas células inflamatórias, mas com importante angiogênese capilar e microtrombos, aglomerados nodulares de pequenos capilares misturados com hemácias e depósitos de hemossiderina na derme. A ausência de infiltrado perivascular suficiente ou leucocitoclasia argumenta contra vasculite, favorecendo mais um processo trombótico. A microangiopatia livedóide acomete principalmente mulheres jovens e de meia idade. Pode ser idiopática, ou estar associada a alterações na coagulação, incluindo mutação no fator $\mathrm{V}$ de Leiden, deficiência da proteína $\mathrm{C}$, aumento na homocisteína plasmática, anormalidades na fibrinólise, ativação plaquetária e síndrome do anticorpo antifosfolípide (SAF). Nós apresentamos um caso de uma paciente com microangiopatia livedóide, associada à presença de SAF com múltiplas úlceras em membros inferiores, que só apresentou melhora clínica após a anticoagulação plena com warfarina e posterior associação com danazol. A microangiopatia livedóide pode representar uma manifestação clínica inicial de um grupo de doenças que causam vasculopatia oclusiva. Logo, todo paciente deve ser investigado para presença de anticorpo antifosfolípide ou de outra causa de trombofilia.

Palavras-chave: microangiopatia livedóide, síndrome anticorpo antifosfolípide, trombofilia.

\begin{abstract}
Livedoid microangiopathy is a chronic segmental hyalinizing syndrome of dermal blood vessels, of unknown origin, that affects mainly the lower limbs. Histopathologically, both initial as well as late lesion are characterized by few inflammatory cells infiltrate, with prevalent capillary angiogenesis and microthrombi, agglomerate of small capillaries, and dermal deposits of hemosiderin. The absence of a substantial perivascular infiltrate or leukocytoclasia argues against vasculitis, favouring a thrombotic process. Livedoid microangiopathy attacks mainly young and middle-aged women; can be idiopathic, or associated with coagulation alterations including the factor $V$ Leiden mutation, protein $C$ deficiency, increased plasmatic homocysteine, fibrinolysis abnormalities, platelet activation and antiphospholipid antibody syndrome (APS). We describe a case of a patient with livedoid microangiopathy associated with the presence of APS with multiple ulcers in the lower limbs who showed a clinical improvement only after total anticoagulation with warfarin and association with danazol. Livedoid vasculitis can represent an initial clinical manifestation of a group of diseases which cause occlusive vasculopathy; so, every patient should be investigated for the presence of antiphospholipid antibody or of another cause of thrombophilia.
\end{abstract}

Keywords: livedoid microangiopathy, antiphospholipid syndrome, thrombophilia.

Disciplina de Reumatologia da Universidade de Santo Amaro (UNISA) São Paulo. Recebido em 21/01/2005. Aprovado, após revisão, em 21/07/2005.

1 - Residente do Serviço de Reumatologia da Universidade de Santo Amaro (UNISA) São Paulo/SP.

2- Professora Titular do Serviço de Reumatologia da Universidade de Santo Amaro (UNISA) São Paulo/SP.

3- Preceptora do Serviço de Reumatologia da Universidade de Santo Amaro (UNISA) São Paulo/SP.

Endereço para correspondência: Carla Munhoz Sanches, Av. Brasília, 24, Jardim Progresso, Santo André, CEP 09180-260, SP, Brasil, e-mail: carlasanches@globo.com 


\section{INTRODUÇÃO}

A microangiopatia livedóide foi originalmente descrita em 1967 por Bard e Winkelman ${ }^{(1)}$ como "vasculite livedóide", uma síndrome de hialinização segmentar crônica dos vasos da derme, de causa desconhecida, que afeta principalmente os membros inferiores e é clinicamente caracterizada por lesões purpúricas crônicas ou recorrentes em pés e porção distal dos membros inferiores, que progride para ulcerações irregulares, dolorosas, recorrentes, geralmente no início do verão ou do inverno, em associação com livedo reticular ${ }^{(2,3,4)}$. A evolução das úlceras está geralmente associada com cicatrizes atróficas brancas, do tipo porcelana, circundadas por hiperpigmentação e teleangectasias ${ }^{(3,4,5,6)}$. Histopatologicamente, tanto as lesões iniciais quanto as tardias são caracterizadas por infiltrado com escassas células inflamatórias, mas com importante angiogênese capilar e microtrombos, aglomerados nodulares de pequenos capilares misturados com hemácias e depósitos de hemossiderina na derme ${ }^{(4)}$. Os vasos estão espessados com proliferação endotelial, degeneração hialina e trombose focal. Há pouca inflamação, mas o lúmen do vaso está ocluído por proliferação celular em uma matrix fibrinóide ${ }^{(3)}$. A origem da microangiopatia livedóide é desconhecida, mas a ausência de infiltrado perivascular suficiente ou leucocitoclasia argumenta contra vasculite, favorecendo mais um processo trombótico ${ }^{(2)}$. Além disso, a alteração na coagulação é sugerida devido aos achados anormais na atividade fibrinolítica e à resposta de alguns pacientes à terapia fibrinolítica.

\section{RELATO DE CASO}

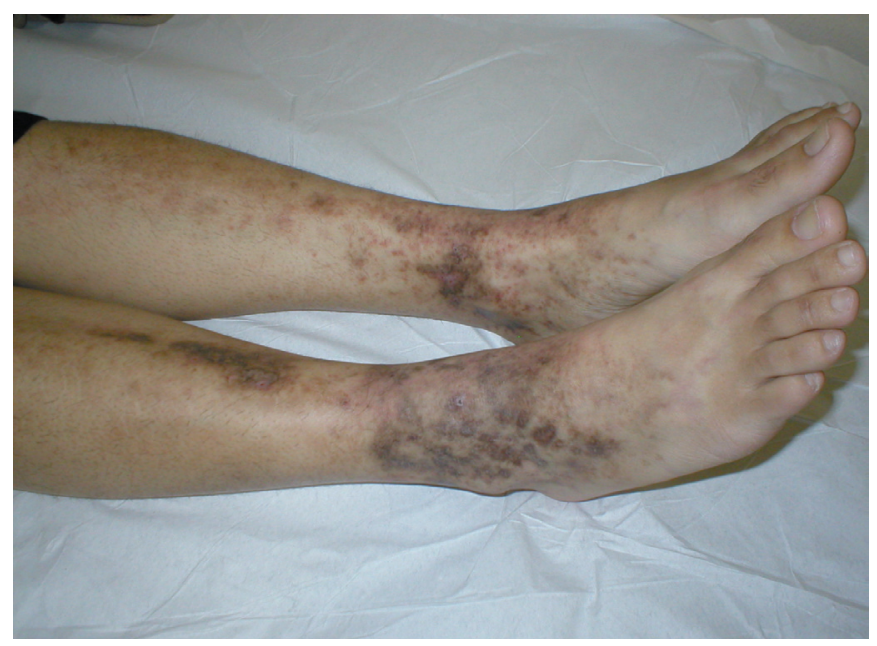

Figura 1 - Lesões purpúricas e pequenas úlceras em tornozelos de paciente com microangiopatia livedóide antes de iniciar o tratamento
Paciente de 24 anos de idade, sexo feminino, branca, escrituraria. Há três anos iniciou com lesões eritematosas e edematosas em região distal de MMII de aspecto livedóide, que ulceravam com a evolução (Figura 1). Realizou vários tratamentos no período de um ano e meio com diferentes especialistas usando: prednisona, deflazacort, difosfato de cloroquina, hidroxicloroquina, pentoxifilina, metotrexato e dapsona, sem melhora das lesões. Ao exame, apresentava lesões de aspecto livedóide, eritematosas, edemaciadas em região distal de membros inferiores, com várias ulcerações de 0,5 a $1 \mathrm{~cm}$ de diâmetro. Aparelho cardiovascular: PA 100/60 mmHg, freqüência cardíaca de $60 \mathrm{bpm}$, ausculta com ritmo cardíaco regular, presença de sopro sistólico 1+/4+ em foco mitral e estalido de abertura de válvula mitral. Aparelho respiratório, exame neurológico e abdômen sem alterações.

Exames laboratoriais: $\mathrm{Hb}$ : 13,5 g/dL; Htc: 40\%; leucócitos: $8.000 \mathrm{~mm}^{3}$ 53/6/0/32/0/9; plaquetas: 294.000 $\mathrm{mm}^{3}$; VHS: $10 \mathrm{~mm}$ na primeira hora; glicemia: $91 \mathrm{mg} / \mathrm{dL}$; creatinina: 0,8 mg/dL; TGP: $17 \mathrm{U} / \mathrm{L}$, TGO: $16 \mathrm{U} / \mathrm{L}$; urina I: normal; VDRL: não-reagente; FTA-ABS: nãoreagente; $\operatorname{IgM}: 228.0 \mathrm{mg} / \mathrm{dL}(40.0$ a $250.0 \mathrm{mg} / \mathrm{dL}) ; \operatorname{IgE}$ : $500.0 \mathrm{UI} / \mathrm{mL}$ (menor $150 \mathrm{UI} / \mathrm{mL}$ ); IgA: $476.0 \mathrm{mg} / \mathrm{dL}$ (90.0 a $310.0 \mathrm{mg} / \mathrm{dL}$ ); fator reumatóide: não-reagente; fator antinuclear: não-reagente; anti-SSA: não-reagente; anti-SSB: não-reagente; anti-DNA: não-reagente; antiENA: não-reagente; CH50: $98 \mathrm{U} / \mathrm{mL}$; C3: 147,9 U/mL; C4: 13,5 U/mL; ANCA: negativo; anticoagulante lúpico: 1,13 (menor que 1,15, negativo); TTPA: $36 \mathrm{seg}$ (32 seg); antifosfolípides IgG 1/100; antifosfolípides IgM 1/100. A pesquisa para anticorpos antifosfolípides foi refeita após dois meses e o resultado foi igual ao anterior. Ecocardiograma (10/07/2002): prolapso de valva mitral com insuficiência mínima. Biópsia da lesão cutânea (2001): Fragmento de pele apresentando epiderme com acantose discreta; os vasos dérmicos papilares e da derme reticular exibem alterações fibrinóides de suas paredes e por vezes as suas luzes são obstruídas por trombos hialinos. Há discreto infiltrado inflamatório linfocitário perivascular. Conclusão: vasculite hialinizante (livedóide).

Foi introduzido tratamento com heparina sódica e warfarina sódica, mantendo RNI em torno de 3,0, apresentando inicialmente cicatrização das úlceras e diminuição da dor e do edema. Porém, esporadicamente, as lesões cutâneas recidivavam com menor intensidade. Optou-se pela associação com danazol $100 \mathrm{mg}$, que proporcionou melhora do quadro até o momento. 


\section{DISCUSSÃO}

A microangiopatia livedóide acomete principalmente mulheres jovens e de meia-idade ${ }^{(2,7)}$; pode ser idiopática, ou estar associada a alterações na coagulação incluindo mutação no fator $\mathrm{V}$ de Leiden, deficiência da proteína $\mathrm{C}$, aumento na homocisteína plasmática, anormalidades na fibrinólise, ativação plaquetária e $\mathrm{SAF}^{(8)}$.

A presença dos anticorpos antifosfolípides está associada ao risco de fenômenos trombóticos arteriais, venosos e insuficiência placentária resultando em perdas fetais ${ }^{(9)}$. Várias manifestações cutâneas ocasionadas por oclusão vascular foram descritas em pacientes com SAF. Entre elas estão: livedo reticularis, microangiopatia livedóide, pioderma gangrenoso, tromboflebite, gangrena cutânea, necrose digital, ulcerações cutâneas, linfoma cutâneo de células $\mathrm{T}$, púrpura, hemorragias subungueais, lúpus eritematoso discóide, doença de Degos (papulose atrófica maligna), nódulos cutâneos dolorosos, anetoderma e esclerose sistêmica ${ }^{(4,10,11,12)}$.

Em estudo realizado na Clínica Mayo, 41\% dos pacientes com SAF apresentavam lesões cutâneas como a primeira manifestação clínica da doença e $40 \%$ destes evoluíram com outros fenômenos trombóticos; ressaltando, assim, a importância destas manifestações cutâneas e sua relação com a doença sistêmica ${ }^{(11)}$.

Em estudo prospectivo com 33 pacientes com SAF, 13 apresentavam microangiopatia livedóide ${ }^{(4)}$, sendo que em dois esta manifestação cutânea estava presente junto com o primeiro fenômeno trombótico, isto é, no início da doença. O aspecto histológico observado é de trombose vascular nãoinflamatória ${ }^{(11,13)}$, independentemente se a microangiopatia

\section{REFERÊNCIAS}

1. Bard JW, Wilkemann RK. Livedo Vasculitis. Segmental Hyalinizing vasculitis of the dermis. Arch Dermatol 96: 489-99,1967.

2. Acland KM, Darvay A, Wakelin SH, Russel-Jones R: Livedoid vasculitis: a manifestation of the antiphospholipid syndrome? $\mathrm{Br} \mathrm{J}$ Dermatol; 140: 131-5, 1999

3. Calamia KT, Balabanova M, Perniciaro C, Walsh JS: Livedo (livedoid) vasculitis and the factor $\mathrm{V}$ Leiden mutation: Additional evidence for abnormal coagulation. J Am Acad Dermatol; 46: 133-7, 2002

4. Stephansson EA, Niemi KM, Jouhikainen T, Vaarala O, Palouo T: Lupus anticoagulant and the skin. A long-term follow-up study of SLE patients with special reference to histopathological findings. Acta Derm Venereol; 71: 416-22, 1991

5. Hairston BR, Gibson LE, Drage LA: Treatment of livedoid vasculopathy with low-molecular-weight heparin: report of 2 cases. Arch Dermatol; 139: 987-90, 2003

6. Hegemann B, Helmbold P, Marsch WC: Livedoid vasculitis with ulcerations: the role of antithrombin III deficiency and its therapeutic consequences. Arch Dermatol; 138: 841-2, 2002 livedóide é idiopática ou se está associada à presença de anticorpo antifosfolípide ou de outra causa adquirida ou herdada de trombofilia ${ }^{(11)}$.

Neste relato de caso, a paciente recebeu o diagnóstico de SAF primária, conforme o critério de classificação para SAF, já que apresentou um critério laboratorial, anticorpo antifosfolípide reagente, e um critério histológico, presença de trombos hialinos na biópsia de lesão cutânea ${ }^{(14)}$.

Não existem estudos controlados duplos-cegos para o tratamento da microangiopatia livedóide. Nos relatos ou séries de casos presentes na literatura preconiza-se o uso de anticoagulantes ou de terapia fibrinolítica como heparina em baixas doses, pentoxifilina, danazol, aspirina ou dipiridamol. Corticosteróide, dapsona e vasodilatadores também têm sido utilizados no tratamento da microangiopatia livedóide. Se essa enfermidade está associada à presença de anticorpos antifosfolípides, concordamos com Acland et a ${ }^{(2)}$ que o paciente deva ser anticoagulado para evitar a presença de outros fenômenos tromboembólicos. No entanto, não existe nenhum estudo que confirme este ponto de vista. Ele é embasado apenas na série de casos em que $40 \%$ dos pacientes que apresentaram lesões cutâneas associadas ao anticorpo antifosfolípide desenvolveram posteriormente fenômenos trombóticos sistêmicos ${ }^{(2,11)}$.

A microangiopatia livedóide pode representar uma manifestação clínica inicial de um grupo de doenças que causam vasculopatia oclusiva. Logo, todo paciente deve ser investigado para presença de anticorpo antifosfolípide ou de outra causa de trombofilia, e um tratamento adequado deve ser instituído para evitar maiores complicações sistêmicas.

7. Hsiao GH, Chiu HC: Low-dose danazol in the treatment of livedoid vasculitis. Dermatology; 194: 251-5, 1997

8. Soter NA, Franks Jr AG: The skin. In Kelley Ruddy S, Harris Jr ED, Sledge CB: Textbook of Rheumatology, 6th ed, Philadelphia, WB Saunders, 2001, p. 408

9. Hanly JG: Antiphospholipid syndrome: an overview. CMAJ; 168(13): 1675-82, 2003

10. Bick RL: Antiphospholipid thrombosis syndromes. Hematol Oncol Clin North Am; 17:15-47, 2003

11. Asherson RA, Cervera R: Antiphospholipid syndrome. J Invest Dermatol; 100: 21S-27S, 1993

12. Gibson GE, Su WP, Pittelkow MR: Antiphospholipid syndrome and the skin. J Am Acad Dermatol; 36: 970-82, 1997

13. Lockshin MD: Antiphospholipid Antibody Syndrome. In Kelley Ruddy S, Harris Jr ED, Sledge CB: Textbook of Rheumatology, 6 th ed, Philadelphia, WB Saunders, 2001, p. 1145-52.

14. Wilson WA, Gharavi AE, Koike $\mathrm{T}$ et al. International Consensus Statement on Preliminary Classification Criteria for Definitive Antiphospholipid Syndrome. Arthritis Rheum 42: 1309-1311, 1999. 